\title{
Transformation to Eco-Agri Tourism: The Case of Casile, Cabuyao City, Laguna, Philippines
}

\author{
Troy P. Tuzon ${ }^{1}$, Lira Jane A. Hilao ${ }^{2}$, Irish Renerie D. Marana ${ }^{3}$, Kevin N. Villalobos ${ }^{4}$, Enrico \\ Garcia $^{5}$, Merlita C. Medallon ${ }^{6}$ \\ ${ }^{1,4}$ Faculty of the College of International Tourism and Hospitality Management, Lyceum of the \\ Philippines University - Laguna, Calamba City, Laguna, Philippines \\ ${ }^{2,3}$ Students of the College of International Tourism and Hospitality Management, Lyceum of the \\ Philippines University - Laguna, Calamba City, Laguna, Philippines \\ ${ }^{5}$ Faculty of the College of Arts and Sciences, Lyceum of the Philippines University - Laguna, \\ Calamba City, Laguna, Philippines \\ ${ }^{6}$ Research Director, Lyceum of the Philippines University - Laguna, Calamba City, Laguna, \\ Philippines
}

\begin{abstract}
The study was conducted to determine the acceptability of the residents of Barangay Casile, Cabuyao, Laguna, Philippines in transforming their locality into an ecoagri tourism site. A total of 241 residents participated in the data collection using a survey questionnaire and interviews. Barangay Casile is an agricultural area and is also noted for its natural heritage such as the Matang Tubig River and Falls and the Marcos Twin Tower. Because of this, the local government unit of Cabuyao City plans to develop the area as a nature- based tourism destination specifically as an eco-agri tourism site. The survey revealed that the respondents agreed on the proposition of transforming their area into agri-tourism site. Cultural acceptability ranks the highest which means that the locals are open on the possible effects on their culture that the development could bring them. Economic and social acceptability were also ranked high because of the income they could get from the influx of tourists. Environmental acceptability is the least agreeable because most of the respondents were environment sensitive and are concerned with the changes to the natural façade of their area. It can be concluded that agri-tourism development involving local residents provides control over the development and management of the project.
\end{abstract}

\section{Introduction}

Eco-agri tourism is a combination of 'Ecotourism' and 'Agri-tourism'. This type of tourism aims to sustain the culture and nature of the place while promoting agriculture as the tourism attraction. Both ecotourism and agri-tourism were considered as Nature- based Tourism because it both depends directly to nature. However, eco-agri tourism mainly focus on sustainable yet community-based tourism, which is the current trend within the tourism industry nowadays. This type of tourism requires the participation of the local community as the host and as attraction itself.

Nature-based tourism is the type of tourism that relies on experiences directly related to natural attractions. It directly depends on nature and includes ecotourism, adventure tourism, extractive 
tourism; farming or agri-tourism, wildlife tourism and nature retreats. Nature-based tourism is the trend because tourists are becoming more environment- sensitive. Nature-based tourism can indirectly promote conservation. Natural sites include topography, water, wildlife, protected natual areas, climate and vegetation and are pull factors of ecotourism [1].

The United Nations International Year of Ecotourism (IYE) of 2002 marked the rise of ecotourism as a new market opportunity advocating a form of sustainable development in rural developing world [2]. The main purpose of the declaration was to set preliminary agenda for the development of ecotoursim activities in the context of sustainable development.

In the Philippines, there are a lot of natural resources that are identified as tourist attractions. There are still a lot that could still be transformed into a nature-based tourism site. Barangay Casile is one of them. Located in the Cabuyao City, a town south of Manila, the community has promising resources that could be considered for tourist attraction. The area is known for its agricultural products and its natural heritage, the Matang Tubig River and Falls. It is also the site of the Marcos Twin Mansion. It is also characterized with highlands and cool breeze with average daily temperature of around $22^{\circ}$ to $24^{\circ} \mathrm{C}$ [3]. It is strategically located and is accessible via land travel. Because of these, the local government of embarked in developing the areas as a nature-based tourism destination. However, there is a need need to integrate the public and stakeholder input in environmental decision-making.

The residents of Barangay Casile prefers to have community based tourism rather than commercial based tourism, according to the report of the local government unit. The residents want to stay as rural as they are to maintain their local lifestyle and culture. With this scenario, the study was conducted to determine the acceptability of the residents to transform their locality into an agritourism site. By getting their responses, the local government planners may have empirical data to show that the program has the approval of the local people.

\subsection{Importance of the local people}

According to Philippine Council for Agriculture, Forestry and Natural Resources Research and Development (PCARRD), there are three reasons why locals are important to be considered in monitoring and evaluating of an eco-tourism project [4]. First, local people make excellent information gatherers and possess a great deal of local knowledge. Second, local participation helps establish a stronger link between the planning and management of ecotourism and its beneficiaries or local stakeholders. Lastly, involving local people in the monitoring and evaluation process motivates them to plan and manage activities in a sustainable manner. Another study stated that tourists view indigenous cultures and local communities as products of the tourism experience that exist to be consumed [5].

Majority of the residents $(65.6 \%)$ of Casile have been residing in the area for 13 or more years. Most of them are earning Php3,000 and below (41.9\%) from farming (30.3\%). Most of the residents are unemployed $(26.1 \%)$. Those who had reached the elementary level $(17.6 \%)$ would most likely belong to the aforementioned groups. For those who had attained at least seconday school (50.2\%), they could get work in factories (12.0\%). Given this demographic profile, opening new avenues for earning is welcome by the residents. Opportunities for new income generating activities will not be declined. Benefits can be gained by the residents if and when the area is open for tourists. On the other hand, the area and its residents may be vulnerable to some risks and changes.

The local government should be able to weigh the benefits and risks of the transformation plan. The local residents are directly affected by any of the good or bad results it may bring. Getting the insights of the local residents is deemed necessary. This will provide a sense of ownership to whatever decisions may be arrived at. The sustainability of the site will depend on how the community handled it. The attitude of the residents towards the development is parallel to the satisfaction level of the tourists. The locals are the host, they are one of the stake holders of tourism development and their participation is very important for this type of program. 


\subsection{Opportunities for eco-agri tourism development}

Ecotourism development poses both opportunities and threats to the natural and social environments. If properly planned and implemented, ecotourism can easily result in positive impacts and create opportunities. Otherwise, it may threaten the natural resources and the local society as well. This is the same thing with eco-agri tourism development, if everything is properly managed and controlled, negative impacts would be lessened and would produce favorable opportunities [6].

Agritourism is a form of tourism where tourists experience traditional rural hospitality, nature and cultural experinces while helping the local community maintain their agricultural viability and diversify economically [7]. The development of agritourism varies in particular places. Considered as a new form of tourism it provides a supplementary commercial activity on local farms. In other countries, like in Indonesia, rural toursim developed in the plantation areas of Sumatra and Java. In Korea, farm tourism was developed through cooperative actions by households. In Malaysia, government funding supports agritourism centers for recreation and education [8]. In New Zealand, short stay volunteering on organic farms result in improved care and concern for the natural environment, support for organic movement and self-development among visitors [9].

Some of the positive impacts and opportunities offered by ecotourism according to Philippine Council for Agriculture, Forestry and Natural Resources Research and Development (PCARRD) are revenue generation, employment opportunities, stronger economy, environmental education, pride and appreciation.

Revenue comes from entrance or visitor use fees, which are charged directly to visitors or tourists for accessing and performing specific activities or for using special equipment in an ecotourism site. Creation of job opportunities is, more often than not, the biggest gain from operating tourism or an ecotourism project [10]. There will be hiring for guides, guards, office staff, or managers for tourism related activities increase. More jobs means stronger economy. Ecotourism helps boost economics at the local, regional, and national levels. Ecotourism offers several ways in promoting environmental education. An example is during an exciting nature hike for instance, visitors are eager to learn about the local habitats. The interest, attention, and appreciation shown by visitors and tourists for local resources and cultural practices, is a manifestation of increased awareness and appreciation of local heritage and natural wealth [6].

With numbers of opportunities from eco-agri tourism, there are also lots of threats because the opportunities once mismanaged will be problems. Some of them are environmental degradation, economic instability, crowding and excessive development.

Environmental degradation is a problem most commonly associated with tourism because visitors may destroy the very resources they come to see [6]. The economic instability is also a problem because ecotourism can be an unstable source of income. Many factors are completely outside the control of local communities yet it affects levels of visitation and tourist demand. Tourists may start to compete with residents for space and is the start of crowding. Although development is a positive consideration, an excessof it may pose a major problem when a location becomes a popular tourist destination. Local businesses must be created through lodging, restaurants, and other services to cater to visitors' needs. With such, other environmental, cultural and social issues may prevail.

\subsection{Theoretical framework}

This study is anchored on two theories, Tourism Development Theory and Social Exchange Theory. The Tourism Development Theory shows the importance of understanding the local resident's reaction towards the tourism development. It states that the factor that may influence their reactions is essential in achieving a host community support for tourism development. The resident's support is tied to economic, social, cultural and environmental consequences. The principle of the study states that total tourism impact has four impact factors, and each impact factor influences the perception of other impact factors and the perceived total impact in varying degrees and different directions [10].

Social Exchange Theory [11] proclaims that residents are likely to participate in an exchange with tourists if they believe that they would likely gain benefits without incurring unacceptable costs. If 
residents perceive that the positive impacts of tourism development will be greater than the negative impacts, they are inclined to be involved in the exchange and, therefore, endorse future tourism development.

\section{Method}

A descriptive research design was used in this study. Data were gathered from 241 local residents using a researcher-developed questionnaire. The questionnaire was validated by experts prior to its administration. The questionnaire is composed of two parts. The first part gathered data on the demographic profile of the residents which is responded to using a provided checklist. The second part consists of statements that were responded to using a 5-point Likert scale. Data elicited in this part shows the level of acceptability of the residents on the transformation of Barangay Casile into an agri-tourism site in the environmental, cultural, social and economic aspects. The survey questionnaires were administered by the researchers. Guided data collection and interviews with key informants was done using an interview guide. The interviewees included some local officials and residents who have lived in the locality for more than ten years. The interviews further strengthen the responses provided in the questionnaire.

\section{Results and discussion}

\subsection{Level of acceptance in terms of environmental, economic, cultural and social aspect}

The survey shows that $57 \%$ of the local residents are open to new environmental projects that will be initiated in their barangay. There will be increasing support from the government for the local projects that will be established in the locality. With these there will be more assistance and benefits that the residents will be able to receive. The residents understand that there will be few changes in their surroundings but they cannot approve of the instance of letting the wildlife in Casile get disturbed. About $34 \%$ of the respondents believe that if there will be a possible increase in waste generation, it would do no good in their place.

This is supported by the statement of one of the caretakers, who said that increase support from the government would be a good idea but they could not accept the possible consequence of ruining their environment. In another interview, it was stated that minimal changes to the environment would be tolerable but not the things that could be detrimental to their natural resources.

The result shows that on the environmental aspect, acceptability is low implying that the respondents don't want their environment to be altered for some reasons. This is in accordance to the statement of one respondent who stated that "whatever happens they want to preserve the maidenhood of their barangay', They are very sensitive when it comes to the environment because a lot of residents of Casile depend on its agriculture as a source of livelihood.

The foregoing concerns had earlier been reported that exploitation of the natural resources had strong negative impacts on the ecological systems and sustainability of the planning of tourism market [12]. Another reported that although local residents agree that tourism has negative impacts and there was a great need to protect rural areas, they preferred to develop the natural attractions first to attract many more tourists and use the financial returns from tourism to protect the natural resources [13]. It was likewise reiterated that even if ecotourism represents one of the more eco-friendlh alternatives for the economic use of natural resources, poor ecotourism management may degrade the natural resources [14].

On the economic aspect, the local residents want to have more opportunities to gain income. About $76 \%$ of the residents agree that opening the locality into a tourism site would provide an increase in opportunities for employment. It would also strengthen the local income from tourism according to $71 \%$ of the residents. It was also agreed that there could be changes in the current type 
of business or occupation that they have. However, $34 \%$ of the respondents claimed that it could also result to increasing price of commodities.

One of the interviewees supported the result of the survey saying that more job opportunities for the locals would bring in more income. It was also mentioned that they are willing to have a change of career if it would lead to having an increase in income. The residents are open to having new jobs aside from farming which will bring additional income to them. On the other hand, another resident suggested that for those who already have jobs, they should continue on what they have started. The result for increasing price of commodities can be compensated with the ability of the residents to have more income and be able to pay for them. Concerns about future job security is compensated by more immediate monetary interests such as getting tips from tourists which eventually may play a role in building environmental appreciation. Tips represent an important supplement to regualr wages and daily bonuses which can account for up to $40 \%$ of a guide's total monthly earnings [15]. In another report, it was reiterated that a key feature of community based agri-tourism is the creation of rewarding, sustainable and relatively well-paid employment [16].

Results of the study concur with the statement that economic benefits are welcome as long as there is ethical business practice, adherence to highest labor standards and development and maintenance of local community infrastructure [17]. The welfare of the residents should be given priority. Ecotourism standards should be generated that stipulate benefits to local communities [18].

On the other hand, since most of the residents are farmers, there is acceptability in the economic aspect. The respondents are open to having new jobs aside from farming which will bring additional income to them. By introducing an immediate and potentially lucrative source of revenue, the growth of agri-tourism throughout the developing world has acted as an incentive for communities to protect and preserve natural areas [19].

Socially, $74 \%$ of the residents accept the fact that their barangay will be more popular if the development will be pursued. This will correspond to increase in security and attention from the government $(71 \%)$. The residents also accept the fact that their population may possibly increase $(51 \%)$ but likewise believe that the increase in noise $(39 \%)$ that their barangay will experience may still be tolerable. This is supported by a resident who stated that it is acceptable for their barangay to be known and to be visited by lots of tourists. There is enthusiasm to welcome visitors who enhanced their sense of pride in the region. However, the thought of having an increase in noise shouldn't happen because the locals are used of having a peaceful place. Foucat [20] found the protection of natural sites as bery important for the development of social aspects such as community cohesion, organization and improvement in the condition of local people's health. Communal rather than individual benefits will be inculcated when young foreign people stay in the locality.

Interviews with local residents revealed the significance of maintaining cultural values. One of the local officials mentioned that they are welcoming the idea of having different groups of people visiting their place to be able to present the local culture and be more appreciative of their own culture. Appreciation of their own culture is still aspired by $72 \%$ of the residents. Opening the area to visitors is a venue to present to other people the local traditions and the way of life. However, the fact that there could be some alterations on their local traditions (58\%) and way of living is not discounted. The residents $(66 \%)$ accept the fact that their perception in life would change because they believe that it could also be helpful. An interviewee said that the possible influence of tourists is acceptable and that the local residents must not be affected by the sudden flow of tourists. It was earlier noted that progressive social and cultural change that stems from tourism has an effect on intergenerational, gender or ethnic conflicts in communities where the status quo is disrupted [21]. Adverse sociocultural impacts associated with codes of conduct and local norms had to be given much attention. Problems are linked to retention of traditional norms and values to the degree of contact with visitors who bring with them a different values and behavior.

Agri-tourism development involving local residents provides control over the development and management of the project. It is known that a major proportion of the benefits will remain within the communities. Community development encourages conservation, environmental education and sustainable use of natureal resources [15]. Community based agr-tourism serve the economic, social, 
cultural and environmental intests of host communities. Empowerment is a process through which "individuals, households, local groups, communities, regions and nations shape their own lives and the kind of society in which they live", [22-23].

\subsection{Demographic factors that affect the acceptability of transforming Casile into an agri-tourism site}

The locals from the age bracket of late adolescence and early young adulthood were the most affected in terms of economic and social because they are the ones who are involved in employment and socialization.

The perception in terms of age can affect in different ways on how people will think and act [24]. They stated that age is also a factor that also affects individual's perception on how they think and act. It also stated that age has a significant relationship with knowledge, attitude and behavior of the respondents.

Gender have significant relationship with the level of acceptance only in terms of social aspect. The culture creates differences in gender since there are behavior, expectation, roles, representation and sometimes values and beliefs that are specific to men and women.

The result shows that married people are more affected by economic and social changes because they usually have families to work for. This is supported by the study [24] who stated that being married drives one to find a job that could support their family necessities.

Educational attainment doesn't have significant relationship with the environmental, social, cultural and economic acceptability because even the local residents who had higher education were not able to have a deeper understanding about eco-agri tourism. The levels of acceptability are slightly correlated and none of them was significant. The result is contradicted by the study [25] which states that the educational attainment of individuals influence their perception about public issues and also contradicted with the study that the educational attainment has a significant relationship with the perception of the respondents [26].

The same with educational attainment, the type of occupation doesn't influence the level of acceptance of the respondents. This is because the development would be beneficial to all kinds of occupation the residents have. The locals were usually farmers and unemployed and they foresee the development of Brgy. Casile as an eco-agri tourism destination would be a big help for them. Environmental, economic, social and cultural acceptability were only slightly correlated and none of them were significant.

The result shows that monthly income does not have significant relationship in terms of environmental, economic, social and cultural aspects. Most of the respondents were earning Php 3000 and below and they are willing to change their current occupation or business for them to have a much better source of income.

Most of the respondents have been living in Brgy. Casile for at least 13 years. Their residency affects their perception in terms of economic and social aspect because of a possible change in source of income and change in the social environment because of the possible influx of tourists. Local residents of Casile were used to having a very peaceful and quiet place.

\section{Conclusion}

The respondents rated all the aspects of acceptability as agreeable but cultural acceptability rates as the highest and environmental acceptability as the lowest. The researchers concluded that environmental acceptability is the least agreeable because most of the respondents are environment sensitive and are concerned with nature. However, cultural acceptability ranks the highest which shows that the local residents are open to the possible effects on their culture that the development could bring them. Economic and social acceptability were also ranked high because of income considerations which is their primary need and if more tourists will come they will have more income. The inputs provided by the residents in this study is a guide to the local government planners on 
tourism development. Careful evaluation of the advantages and disadvantages brought it by ecotourism development should be done. The voice of the residents should be heard in fora and consultative meetings designed for the purpose. Although benefits can be enumerated, it should be considered that it takes a long journey before these can be achieved. The price of the dreamed economic advantage has to be paid with environmental and cultural pay-offs. A more in-depth probing on the issue of transforming Barangay Casile into an eco-agri tourism site should be done.

\section{References}

1. D. Weaver, and L. Lawton, Tourism Management. John Wiley \& Sons, Australia.(2002)

2. J. Butcher, The United Nations International Year of Ecotourism: a critical analysis of development implications. Progress in Dev. Studies 6, 2, 146-156 (2006)

3. Temperature of Cabuyao City. Retrieved March 23, 2013 from http://www.accuweather.com/en/ph/cabuyao-city/262695/weather-forecast/262695

4. PCARRD. Planning and Developing Community- based Ecotourism Projects in the Philippines. (2010).

5. $\quad$ S.Wearing, \& J.Neil, Ecotourism: Impacts, Potentials and Possibilities? (2009).

6. A. Drumm, \& A. Moore, Ecotourism Development: A Manual for Conservation Planners and Manager. (2005).

7. G. Veeck, D. Che \& A. Veeck, America's changing farmscape: A study of Agricultural Tourism in Michigan. The Professional Geographer, 58, 3, 235-248 (2006).

8. H. Choo \& T. Jamal, Tourism on organic farms in South Korea: a new form of ecotourism? J. Sustainable Tourism. 17, 4, 431-454 (2009).

9. A.J. McIntosh, \& B. Bonnemann, S.Willing, Workers on Organic Farms (WWOOF): The alternative farm stay experience? J. Sustainable Tourism, 14, 1, 82-99 (2006).

10. Y.Yoon, D.Gursoy, , \& J.Chen, Validating a tourism development theory with structural equation modeling. Tourism Mgt. 22, 4, 363-372. (2006)

11. J.H. Turner, Handbook of sociological theory. Kluwer Academic/Plenum Publishers, New York.(2002)

12. P. Chufamanee \& J. Lønholdt, Application of integrated environmental management through the preparation of an environmental action programme: Case study from the Songkhla Lake Basin in southern Thailand Lakes and Reservoirs. Research and Management. 6, 4, 323 (2001)

13. H. Goodwin \& D. Roe, Tourism, Livelihoods and Protected Areas: Opportunities for Fairtrade Tourism in and Around National Parks. International Journal of Tourism Research. Res. 3, 377-391 (2001)

14. W.J. Li, Environmental management indicators for ecotourism in China's nature reserves:A case study in Tianmushan Nature Reserve. Tourism Management. 004,25, 5, 559-564. (2003).

15. N. Kontogeorgopoulos, Community-Based Ecotourism in Phuket and Ao Phangnga, Thaiiand: Partial Victories and Bittersweet Remedies. J. Sustainable Tourism. 13, 1 (2005)

16. R. Scheyvens, Promoting women's empowerment through involvement in ecotourism: Experiences from the Third World, J. Sustainable Tourism 8, 3,232-^9 (2000)

17. M. Honey, (ed.) Ecotourism and Certification.. Washington, DC: Island (2002).

18. L.K. Medina, Ecotourism and Certification: Confronting the Principles and Pragmatics of Socially Responsible Tourism. J. Sustainable Tourism. 13, 3 (2005)

19. J. Yamagiwa, Bushmeat poaching and the conservation crisis in Kahuzi-Biega National Park, Democratic Republic of the Congo. J. Sustainable Forestry 16, 3-1, 115-35 (2003).

20. V.S.A. Foucat. Community-based ecotourism management moving towards sustainability, in Ventanilla, Oaxaca, Mexico.Ocean \& Coastal Management, 45, 8, 511-529. (2002).

21. C. Fabricius, Towards strengthening collaborative ecosystem management: Lessons from environmental conflict and political change in southern Africa. Journal of Tiic Royai 
Society of New Zealand 31, 4, 831 (2001).

22. R. Scheyvens, Tourism for Development: Empowering Communities. Harlow: Prentice Hall. (2002).

23. D. Timothy, Tourism and community development issues. In R. Sharpley and D. Telfer (eds) Tourism and Development: Concepts and Issues. Clevedon: Channel View, 149-64 (2002).

24. N.Alcasid, R.Barrera, \& C.Marfic, The Perception of Guests Olympic Point Island Resort in Tingloy, Batangas towards the Effectiveness of Advertising Tools for Local Beaches. Lyceum of the Philippines- Laguna. (2011).

25. M. King \& A. Mendoza, Effects of RTV exposure to the culture of Mangyans in Safa, Sabang, Panimalayan, Oriental Mindoro. Lyceum of the Philippines Laguna. (2012).

26. A. Delos Santos, S.J. Alcalde \& A.F. Marasigan, The Perceived Effects of Indigenous Tourism in The Lives of Selected Aetas in Pastolan Village, Hermosa Bataan, Subic Bay Philippines. Lyceum of the Philippines- Laguna. (2013). 